\title{
Predicting response to benralizumab in chronic obstructive pulmonary disease: analyses of GALATHEA and TERRANOVA studies
}

DOI:

10.1016/S2213-2600(19)30338-8

\section{Document Version}

Accepted author manuscript

Link to publication record in Manchester Research Explorer

Citation for published version (APA):

Criner, G. J., Celli, B. R., Singh, D., Agusti, A., Papi, A., Jison, M., Makulova, N., Shih, V. H., Brooks, L., Barker, P., Martin, U. J., \& Newbold, P. (2019). Predicting response to benralizumab in chronic obstructive pulmonary disease: analyses of GALATHEA and TERRANOVA studies. The Lancet Respiratory Medicine.

https://doi.org/10.1016/S2213-2600(19)30338-8

\section{Published in:}

The Lancet Respiratory Medicine

\section{Citing this paper}

Please note that where the full-text provided on Manchester Research Explorer is the Author Accepted Manuscript or Proof version this may differ from the final Published version. If citing, it is advised that you check and use the publisher's definitive version.

\section{General rights}

Copyright and moral rights for the publications made accessible in the Research Explorer are retained by the authors and/or other copyright owners and it is a condition of accessing publications that users recognise and abide by the legal requirements associated with these rights.

\section{Takedown policy}

If you believe that this document breaches copyright please refer to the University of Manchester's Takedown Procedures [http://man.ac.uk/04Y6Bo] or contact uml.scholarlycommunications@manchester.ac.uk providing relevant details, so we can investigate your claim.

\section{OPEN ACCESS}




\section{INTRODUCTION}

Exacerbation reduction is a primary treatment goal for patients with chronic obstructive pulmonary disease (COPD).${ }^{1}$ However, $30-50 \%$ of patients receiving triple combination maintenance therapy with inhaled corticosteroids (ICS)/long-acting $\beta_{2}$-agonists (LABA)/longacting muscarinic antagonists (LAMA) continue to experience moderate or severe COPD exacerbations. ${ }^{2}$ Additional treatment options are limited for these patients. ${ }^{2,3}$

COPD is a heterogeneous disease. Different inflammatory mechanisms and pathways may contribute to the pathology and clinical outcomes. ${ }^{4}$ Eosinophilic inflammation may be an important component in the pathogenesis of a subpopulation of patients with COPD. ${ }^{5-8}$ An estimated 30-40\% of patients with COPD have elevated concentrations of eosinophils in the airway as measured by sputum induction. ${ }^{6,9-12}$ Elevated sputum eosinophil counts for patients with COPD are associated with decreased forced expiratory volume in 1 second $\left(\mathrm{FEV}_{1}\right)$ percentage predicted and greater incidence of exacerbations requiring corticosteroid treatment. ${ }^{13}$ In addition, patients with airway eosinophilia have greater airway wall thickening and air trapping than patients with low sputum eosinophil counts. ${ }^{13-15}$

A relationship exists between sputum and blood eosinophil counts for patients with COPD, indicating that greater blood eosinophil counts may be a surrogate of eosinophilic inflammation of the airway epithelia. ${ }^{13,14,16-18}$ Blood eosinophil concentration $2 \%$ or greater for patients with COPD has been identified to have a positive predictive value of $90 \%$ for an increased eosinophil concentration in induced sputum. ${ }^{19}$ Elevated blood eosinophil counts for patients with COPD are 
associated with increased exacerbation risk and greater ICS treatment efficacy. ${ }^{2,19-24}$ Therefore, decreasing blood eosinophil counts for patients with elevated blood eosinophil counts may reflect reductions in airway eosinophilia and provide clinical benefit.

Benralizumab is indicated for add-on maintenance treatment of patients with severe, eosinophilic asthma. ${ }^{25,26}$ It significantly reduces exacerbation rates and improves lung function and healthrelated quality of life (HRQOL) for these patients. ${ }^{27-29}$ For patients with asthma, benralizumab induces direct, rapid, and nearly complete eosinophil depletion by antibody-dependent cellmediated cytotoxicity. ${ }^{27,28,30}$ The same effect is observed for patients with COPD and elevated blood eosinophil counts. ${ }^{31}$ However, for patients with COPD, benralizumab failed to significantly reduce exacerbation rates (primary endpoints) or improve pre-bronchodilator (BD) $\mathrm{FEV}_{1}$ relative to placebo, regardless of baseline blood eosinophil counts, in two phase 3 clinical trials. ${ }^{31}$ In the GALATHEA phase 3 trial for patients with baseline blood eosinophil counts 220 cells per $\mu \mathrm{L}$ or greater (primary analysis population), rate ratios (RRs; $95 \%$ confidence interval [CI]) for annual exacerbations were $0.96(0.80$ to 1.15$)$ and $0.83(0.69$ to 1.00$)$ for benralizumab $30 \mathrm{mg}$ and $100 \mathrm{mg}$ every 8 weeks (Q8W; first three doses every 4 weeks [Q4W]), respectively, versus placebo. ${ }^{31}$ In the TERRANOVA phase 3 trial for the same primary analysis population, RRs (95\% CI) were $0.85(0.71$ to 1.01$), 1 \cdot 04(0.88$ to 1.23$)$, and $0.93(0.78$ to $1 \cdot 10)$ for benralizumab $10 \mathrm{mg}, 30 \mathrm{mg}$, and $100 \mathrm{mg}$ Q8W versus placebo, respectively. ${ }^{31}$ Given the nonsignificant results for the primary endpoints in GALATHEA and TERRANOVA, results for further analyses of these data could not be considered statistically significant. However, benralizumab $100 \mathrm{mg}$ Q8W did reduce severe exacerbations relative to placebo with RRs (95\% 
CI) of $0.57(0.36$ to 0.91$)$ and $0.68(0.46$ to 1.00$)$ in GALATHEA and TERRANOVA, respectively. ${ }^{31}$

As part of a prespecified exploratory analysis, we hypothesised that identifiable clinical features, together with elevated peripheral blood eosinophil counts, could help identify patients with COPD likely to have greater benralizumab treatment effect. Accordingly, we evaluated individual study and pooled results from GALATHEA and TERRANOVA to identify potential baseline clinical and physiological characteristics of patients demonstrating benralizumab treatment effect on reduction of moderate and severe COPD exacerbations, to generate a hypothesis for identifying patients with COPD who are likely to benefit from benralizumab treatment in future clinical trials. 


\section{METHODS}

\section{Ethics}

The protocols for the GALATHEA and TERRANOVA trials were approved by independent ethics committees of the trial centres or central institutional review boards. ${ }^{31}$ These studies were conducted in accordance with the principles of the Declaration of Helsinki. All patients provided written informed consent.

\section{Exacerbations}

Definitions of COPD exacerbations for these pooled analyses were the same as those used in the original clinical trials. ${ }^{31}$ Exacerbations were defined as symptomatic worsening of COPD for at least 2 days that resulted in the use of systemic corticosteroids ( 3 days or longer) and/or antibiotics and/or hospitalisation or COPD-related death. Exacerbations resulting in hospitalisation or death were considered severe.

\section{Endpoints}

Annual exacerbation rate (AER) for benralizumab versus placebo was the primary endpoint evaluated in these analyses. The key secondary endpoints were change from baseline in $\mathrm{FEV}_{1}$ and St. George's Respiratory Questionnaire (SGRQ) total score.

\section{Study population}

Patients included in these analyses were enrolled in GALATHEA and TERRANOVA, were aged 40-85 years, and had moderate to very severe airflow limitation, with a history of at least two 
exacerbations or one severe exacerbation in the year before enrolment despite receiving treatment with dual therapy (ICS/LABA or LABA/LAMA) or triple therapy (ICS/LABA/LAMA). Patients were enrolled 2:1 on the basis of blood eosinophil count (220 cells per $\mu \mathrm{L}$ or greater $v s$ less than 220 cells per $\mu \mathrm{L}$ ) and allocated $1: 1: 1$ or $1: 1: 1: 1$, respectively, to receive placebo or benralizumab subcutaneously (30 mg or $100 \mathrm{mg}$ Q8W [first three doses Q4W] in GALATHEA; $10 \mathrm{mg}, 30 \mathrm{mg}$, or $100 \mathrm{mg}$ Q8W [first three doses Q4W] in TERRANOVA) for 56 weeks. Because benralizumab $10 \mathrm{mg}$ Q8W was used in the TERRANOVA trial only, these patients were not included in the pooled analyses. Full details of these studies have been published. $^{31}$

\section{Statistical analyses}

We performed analyses with pooled data, as well as individual trial data, for patients who participated in the GALATHEA and TERRANOVA phase 3 clinical trials and received placebo or benralizumab (30 mg or $100 \mathrm{mg}$ Q8W). Given the hypothesis-generating nature of these analyses, evidence of consistent findings replicated across trials was used to support that results were less likely to have occurred by chance alone. We used different statistical analysis methods to identify efficacy-associated factors that were consistent across methods, studies, and benralizumab dosages. Analyses were conducted in SAS version 9.2 (SAS Institute Inc, Cary, NC, USA) and R version 3.2.4 (The R Foundation, Vienna, Austria). The primary results of the main trials have been reported. ${ }^{31}$

A structured exploration was performed to identify baseline factors (continuous or categorical) that ranked as most indicative of potential treatment effect in the individual trials and for the 
pooled population. Gradient-boosting models were used to rank factors for their relative influences or impacts on exacerbation rate within the treatment arms, and virtual twins analyses were used to identify the most influential predictors that differentiated treatment effect between benralizumab and placebo groups. Importantly, these methods do not require predefining thresholds for continuous parameters such as post-BD FEV ${ }_{1}$ or baseline blood eosinophil count. Factors used in the structured exploration included prespecified clinical variables and accounted for correlation of factors across runs, such that potential factors that may correlate with another factor were not both included in the same analysis run (e.g., post-BD FEV 1 /forced vital capacity $[\mathrm{FVC}]$ was not run at the same time as post-BD FVC percentage predicted normal [\% PN]). The factors used were post-BD $\mathrm{FEV}_{1} \% \mathrm{PN}$, post-BD forced expiratory vital capacity $\% \mathrm{PN}$, post-BD $\mathrm{FEV}_{1} / \mathrm{FVC}$, percentage reversibility, sex, age, race, country, baseline blood eosinophil count, COPD medication (dual $v$ s triple therapy), number of prior exacerbations, number of prior severe exacerbations, concurrent asthma, history of asthma, COPD-specific comorbidity test (COTE) index, nicotine use status, nicotine consumption, COPD Assessment Test total score, rhinitis diagnosis, emphysema diagnosis, chronic bronchitis diagnosis, oxygen cost of breathing diagnosis, and time since COPD diagnosis. These factors were arranged into three structured analysis runs, with no more than 19 variables in any one run (table 1). The structured exploration was conducted with the pooled data from both trials and also separately by trial to allow for identification of predictors that were consistently most influential in both trials.

Predictors that ranked as highly indicative of a potential treatment effect in the structured exploration were further analysed to identify whether they were negatively or positively predictive of treatment effect. AER reduction was estimated from a negative binomial model, 
with adjustments for treatment, trial (in analyses pooled across studies), region, and number of prior exacerbations for subgroups of interest. Locally weighted smoothing regression (LOESS) plots and subgroup analyses by quartile were used to further evaluate the relationship between continuous variables and exacerbation rate and to identify an appropriate threshold associated with treatment effect. Results of these analyses were presented as forest plots to illustrate differences in treatment effect over placebo relative to those observed for the overall primary population. Results were pooled across studies to obtain more accurate estimates of the relationship between efficacy endpoints and baseline clinical characteristics of patients by calculating the estimated pooled treatment effect (RRs) and corresponding 95\% CIs for benralizumab $30 \mathrm{mg}$ and $100 \mathrm{mg}$ Q8W versus placebo.

Our analyses were based on baseline characteristics of the primary analysis populations in GALATHEA and TERRANOVA, composed of patients with baseline blood eosinophil counts 220 cells per $\mu \mathrm{L}$ or greater. However, analyses were also performed for patients with blood eosinophil counts less than 220 cells per $\mu \mathrm{L}$ and for the overall population, regardless of baseline blood eosinophil count. Analyses of the effect of benralizumab on AER reduction versus placebo for patients with blood eosinophil counts 300 cells per $\mu \mathrm{L}$ or greater and less than 300 cells per $\mu \mathrm{L}$ were also performed.

\section{Role of the funding source}

The funders of this study participated in the study design and data analysis. All authors had access to the data and reviewed and approved the manuscript for submission. The corresponding 
author had full access to all data in the study and had final responsibility for the decision to submit the paper for publication. 


\section{RESULTS}

\section{Patient population}

The overall trial populations in GALATHEA and TERRANOVA comprised 1,656 and 2,254 patients, respectively. The average age of patients in the pooled data set was $65 \cdot 3$ years, and 1,333/3,910 (34\%) of patients were female (table 2). Most patients $(2,529 / 3,910 ; 65 \%)$ were receiving triple maintenance therapy, and 1,253/3,910 (32\%) were current nicotine users (table 2).

\section{Factors associated with benralizumab treatment effect on annual exacerbation rate reduction, individual trial data sets}

In both the GALATHEA and TERRANOVA trials, influential and consistent covariates for predicting effects on AER for patients with baseline blood eosinophil counts 220 cells per $\mu \mathrm{L}$ or greater included the number of exacerbations in the prior year and baseline lung function measures such as post-BD response \% PN (figure 1). Some covariates were strongly influential predictors in only one study but not in the other, and this was later confirmed in the pooled data structured analysis. For example, COTE index was a strongly influential predictor in the TERRANOVA study for benralizumab $100 \mathrm{mg}$ Q8W versus placebo, but this was not replicated in the GALATHEA study. Therefore, COTE index was not selected as a covariate for further analyses. In corresponding analyses of the full data sets containing patients across categories of baseline blood eosinophil counts, number of prior exacerbations and baseline lung function measures were also consistently identified as covariates for predicting effects on AER. In addition, baseline blood eosinophil counts, in general, appeared more influential for patients in 
the full analysis set (relative influence of approximately 5-10\%; figure S1) than it did for the population with baseline blood eosinophil counts 220 cells per $\mu \mathrm{L}$ or greater (relative influence $<5 \%$; figure 1). This indicates greater treatment effect for patients with baseline blood eosinophil counts 220 cells per $\mu \mathrm{L}$ but no clear improvements with increasing blood eosinophil counts above that cut off.

Further analyses of the identified influential predictors were conducted by quartiles to identify their directional influences. There was a greater AER reduction identified for patients with baseline blood eosinophil counts 220 cells per $\mu \mathrm{L}$ or greater receiving benralizumab $100 \mathrm{mg}$

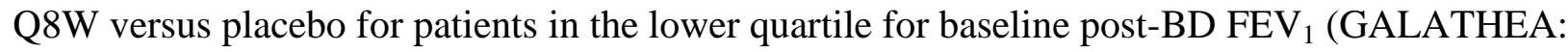
post-BD FEV 1 less than 33.2\% PN, RR [95\% CI]: 0.69 [0.50 to 0.96]; TERRANOVA: post-BD $\mathrm{FEV}_{1}$ less than $33 \cdot 1 \% \mathrm{PN}, \mathrm{RR}$ [95\% CI]: 0.71 [0.53 to 0.95]; figure 2a). Analysis of the predictive factor baseline post-BD response indicated greater AER reduction for patients in the upper quartile (GALATHEA: post-BD response of 17.5\% PN or greater, RR [95\% CI]: $0 \cdot 57$ [0.40 to $0 \cdot 80]$; TERRANOVA: post-BD response of $16 \cdot 2 \% \mathrm{PN}$ or greater, RR [95\% CI]: 0.73 $[0 \cdot 53$ to $1 \cdot 01]$; figure $2 b)$.

We also explored effects on AER reduction by baseline post-BD response according to whether patients met the clinical definition of reversibility (defined as post-BD response greater than $12 \%$ and a 200-mL increase in $\mathrm{FEV}_{1}$ ). There was greater AER reduction with benralizumab $100 \mathrm{mg}$ Q8W versus placebo for patients with baseline post-BD $\mathrm{FEV}_{1}$ response $15 \%$ or greater independent of clinical reversibility status. An equivalent reduction of AER was observed for patients who had post-BD $\mathrm{FEV}_{1}$ response $15 \%$ or greater and also achieved clinical reversibility 
status versus those who met post-BD $\mathrm{FEV}_{1}$ response $15 \%$ or greater but did not achieve clinical reversibility status, with RRs $(95 \% \mathrm{CI})$ of $0.61(0.38$ to 0.97$)$ and $0.60(0.40$ to 0.91$)$, respectively, in GALATHEA and $0.78(0.51$ to 1.18$)$ and $0.70(0.43$ to 1.15$)$, respectively, in TERRANOVA (figure 2c).

\section{Factors associated with benralizumab treatment effect on annual exacerbation rate, pooled data set}

In agreement with analyses for the individual GALATHEA and TERRANOVA trials, analysis of pooled data identified number of exacerbations in the prior year and baseline lung function measures, including post-BD response \% $\mathrm{PN}$, as covariates associated with AER reduction for patients with baseline blood eosinophil counts 220 cells per $\mu \mathrm{L}$ or greater (figure 1 ). As in the individual trials, analysis of the full pooled data set consistently identified number of prior exacerbations, baseline blood eosinophil counts, and baseline lung function measures as covariates for predicting effects on AER for patients across the range of baseline blood eosinophil categories (figure S1, Supplementary Appendix page 3).

In the pooled data set, for patients with elevated baseline blood eosinophil counts ( 220 cells per $\mu \mathrm{L}$ or greater), the $\mathrm{RR}$ for annual exacerbations versus placebo was 0.88 (95\% CI 0.77 to 0.99 ) for those receiving benralizumab $100 \mathrm{mg}$ Q8W. The factors identified in the individual studies and pooled data set were examined for benralizumab treatment effect (AER reduction) for the pooled population of patients with elevated blood eosinophil counts (figure 3). Greater treatment effect with benralizumab $100 \mathrm{mg}$ Q8W was observed for patients with a history of three or more exacerbations in the prior year (RR $[95 \% \mathrm{CI}] 0.69[0.56$ to $0 \cdot 83])$, but not with benralizumab 30 mg Q8W (RR [95\% CI] 0.86 [0.71 to $1 \cdot 04])$. The two identified factors related to lung function 
were also associated with greater treatment effects. The RRs $(95 \% \mathrm{CI})$ for benralizumab $100 \mathrm{mg}$ Q8W were $0.76(0.64$ to 0.91$)$ for post-BD FEV 1 less than $40 \% \mathrm{PN}$ and $0.67(0.54$ to 0.83$)$ for post-BD response to short-acting $\beta_{2}$-agonists $15 \%$ or greater (figure 3 ).

We also examined the association of background therapy type (dual or triple) on exacerbation reductions during benralizumab treatment. For patients receiving triple therapy, benralizumab $100 \mathrm{mg}$ Q8W had a greater effect on AER reduction versus placebo with RR (95\% CI) of 0.81 (0.70 to $0 \cdot 94)$, compared with $1.03(0.82$ to $1 \cdot 28)$ for patients receiving dual therapy (figure 3 ). Patients receiving triple therapy tended to have more consistent results across the studies and pooled data set. These factors identified greater treatment effect with benralizumab $100 \mathrm{mg}$ Q8W compared with benralizumab $30 \mathrm{mg}$ Q8W or placebo in reducing AER for patients with baseline blood eosinophil counts 220 cells per $\mu \mathrm{L}$ or greater. Of patients with baseline blood eosinophil counts less than 220 cells per $\mu \mathrm{L}$, no factors were associated with benralizumab treatment effect (figure 4).

\section{Effects of baseline blood eosinophil counts on annual exacerbation rate}

Analysis of pooled data by baseline blood eosinophil count indicated numerically reduced RRs

for annual exacerbations in each blood eosinophil count category above 220 cells per $\mu \mathrm{L}$ for patients receiving benralizumab $100 \mathrm{mg}$ Q8W but indicated no evidence for treatment effect for categories less than 220 cells per $\mu \mathrm{L}$ (figure 5). For patients with baseline blood eosinophil counts 300 cells per $\mu \mathrm{L}$ or greater receiving benralizumab $100 \mathrm{mg}$ Q8W, RR versus placebo (95\% CI) was $0.85(0.74$ to 0.99$)$. Patients with baseline blood eosinophil counts less than 300 
cells per $\mu \mathrm{L}$ receiving benralizumab $100 \mathrm{mg}$ Q8W had an RR versus placebo (95\% CI) of 1.00 $(0 \cdot 87$ to $1 \cdot 14)$, indicating no difference from placebo.

The relationship between baseline blood eosinophil count and exacerbation rate was analysed as a continuous variable for the full analysis sets of GALATHEA and TERRANOVA (figure S2, Supplementary Appendix page 5) and subgroups of patients identified as having greater treatment effect with benralizumab in the pooled data set. These analyses (LOESS plots) indicate that benralizumab treatment effect for patients with three or more exacerbations in the prior year (figure S3, Supplementary Appendix page 6), post-BD FEV ${ }_{1}<40 \%$ predicted (figure S4, Supplementary Appendix page 7), and post-BD response $\geq 15 \%$ (figure S5, Supplementary Appendix page 8) increased marginally with increasing baseline blood eosinophil counts.

\section{Impact of potential predictors on benralizumab treatment effect for annual severe exacerbation rate, pooled data set}

Of patients with elevated baseline blood eosinophil counts ( 220 cells per $\mu \mathrm{L}$ or greater), the RR $(95 \% \mathrm{CI})$ for annual severe exacerbations versus placebo was $0.63(0.47$ to 0.84$)$ for those receiving benralizumab $100 \mathrm{mg}$ Q8W. The factors found to have the greatest influence on reduction in exacerbations with benralizumab relative to placebo were also analysed for their associations with reduction in severe exacerbations (leading to hospitalisation or death) for patients with elevated blood eosinophil counts. Clinical characteristics that indicated the greatest numerical reductions in severe exacerbations between benralizumab $100 \mathrm{mg}$ and placebo (RR [95\% CI]) were post-BD response $15 \% \mathrm{PN}$ or greater $(0 \cdot 43[0 \cdot 24$ to $0 \cdot 75])$, three or more exacerbations in the previous year $(0.54[0.32$ to 0.91$])$, triple therapy $(0.55[0.38$ to 0.78$])$, and 
baseline blood eosinophil counts 300 cells per $\mu \mathrm{L}$ or greater $(0 \cdot 59$ [0.41 to $0 \cdot 85])$. Wide CIs were observed because of the smaller number of severe exacerbation events observed in the studies, but all intervals excluded 1.

\section{Combined factors associated with benralizumab treatment effect on annual exacerbation} rate, pooled data set

Prior exacerbations with airflow obstruction or post-bronchodilator response

Given that the frequency of prior exacerbations was the strongest independent predictor of treatment effect with benralizumab $100 \mathrm{mg}$ Q8W for patients with elevated blood eosinophil counts, we evaluated the predictive effect of additional characteristics in combination with history of exacerbations. A greater AER reduction for patients with post-BD $\mathrm{FEV}_{1}<40 \%$ was observed if patients also had more frequent prior exacerbations (table 3). Patients with more frequent prior exacerbations and post-BD $\mathrm{FEV}_{1}$ less than $40 \%$ had an annual exacerbation RR (95\% CI) of $0.65(0.48$ to $0 \cdot 88)$ for benralizumab $100 \mathrm{mg} \mathrm{Q8W}$ versus placebo, compared with $0 \cdot 89(0.68$ to $1 \cdot 17)$ for patients with two or less prior exacerbations. In contrast, greater post-BD response was associated with more pronounced AER reduction regardless of the number of prior exacerbations (table 3). Patients with post-BD response $15 \%$ or greater receiving benralizumab $100 \mathrm{mg}$ Q8W had RRs (95\% CI) versus placebo of $0.60(0.42$ to $0 \cdot 85)$ and $0.59(0 \cdot 41$ to $0 \cdot 84)$ for those with two or less and three or greater prior exacerbations, respectively.

\section{Prior exacerbations for patients receiving dual or triple inhaled therapy}

History of more frequent exacerbations (three or more in the prior year) and triple therapy each individually were associated with reduced RR for patients receiving benralizumab compared 
with the overall patient population. However, RRs (95\% CI) for benralizumab $100 \mathrm{mg}$ Q8W versus placebo were similar when frequent exacerbation history was combined with dual $(0 \cdot 60$ [0.42 to 0.87$])$ or triple therapy $(0.70$ [0.56 to 0.88$])$ (table 3$)$. Of patients receiving either dual or triple therapy with a history of severe exacerbations receiving benralizumab $100 \mathrm{mg}$ Q8W, RR (95\% CI) versus placebo was $0.59(0.42$ to 0.82$)$ compared with $0.74(0.58$ to 0.94$)$ for patients with no prior severe exacerbations (table 3).

\section{Combination of individual predictors}

Although patients receiving triple therapy did not have a substantially greater treatment effect with benralizumab than those receiving dual therapy, more consistent results across the studies and pooled data set were observed for the patient population receiving triple inhaled maintenance therapy. The subpopulation of patients with baseline blood eosinophil counts 220 cells per $\mu \mathrm{L}$ or greater, receiving triple inhaled therapy, and who had three or more exacerbations (previous 12 months) were most likely to benefit from benralizumab $100 \mathrm{mg}$ Q8W treatment for reduction of AER (RR vs placebo [95\% CI] 0.70 [0.56 to 0.88$]$ ) (table 3). The selection of patients who had experienced severe exacerbations prior to entering the studies resulted in more pronounced AER reduction, but only for patients with frequent prior exacerbations. The addition of the identified baseline lung function factors of post-BD $\mathrm{FEV}_{1}$ less than $40 \%$ or post-BD response $15 \%$ or greater indicated further reduction of AER with benralizumab $100 \mathrm{mg}$ Q8W versus placebo, with reductions of $35 \%$ (95\% CI $12 \%$ to $52 \%$ ) and $41 \%$ (95\% CI $16 \%$ to $59 \%$ ), respectively. However, the addition of baseline post-BD FEV ${ }_{1}$ and post-BD response resulted in a dramatically smaller population for modest further improvement in AER reduction (figure 6). 
Baseline clinical characteristics of the subgroup of patients likely to have the greatest treatment effect with benralizumab are provided in table 2 .

\section{Identification of factors associated with benralizumab treatment effect on pre- bronchodilator forced expiratory volume in 1 second and health-related quality of life, individual trial data sets}

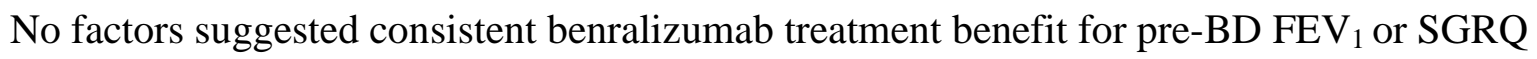
(figure S6, Supplementary Appendix page 9). There was also no evidence for improved pre-BD $\mathrm{FEV}_{1}$ benralizumab treatment effect with increasing blood eosinophil counts or history of exacerbations (figures S7 and S8, Supplementary Appendix pp. 10-11). An increasing treatment effect of benralizumab on SGRQ total score was observed with increasing blood eosinophil counts in both GALATHEA and TERRANOVA, although this did not reach nominal statistical significance (figure S7, Supplementary Appendix page 10). 


\section{DISCUSSION}

In these prespecified exploratory analyses of data from the phase 3 randomised GALATHEA and TERRANOVA trials of benralizumab treatment for patients with moderate to very severe COPD, history of three or more exacerbations in the last 12 months, baseline post-BD FEV less than $40 \%$, and post-BD response of $15 \%$ or more were the strongest and most consistent individual baseline clinical characteristics that appeared to predict treatment effect with benralizumab $100 \mathrm{mg}$ Q8W for patients with baseline blood eosinophil counts 220 cells per $\mu \mathrm{L}$ or greater. However, the degree of lung function impairment and a history of severe exacerbations predicted treatment effect only for patients with a history of three or more exacerbations in the previous 12 months. The combination of blood eosinophil counts 220 cells per $\mu \mathrm{L}$ or greater, three or more exacerbations in the prior year, and triple inhaled therapy identified patients who experienced the greatest treatment effect with benralizumab for reduction of exacerbations. If confirmed prospectively in a future study, these easily identifiable clinical characteristics, together with an elevated blood eosinophil count, could potentially help select patients with greater probability of experiencing treatment effect with benralizumab.

There was a lack of consistent treatment effect for patients with COPD receiving benralizumab $30 \mathrm{mg}$ Q8W. It is unclear why benralizumab $30 \mathrm{mg}$ Q8W, which has demonstrated efficacy in asthma, ${ }^{27,28}$ failed to provide any clinically significant effect in these COPD studies. However, there are important differences between these diseases. COPD is associated with greater structural lung damage than asthma, as well as altered pulmonary blood flow, chronic bacterial colonisation, and presence of different inflammatory cells and mediators. ${ }^{1,2,4}$ These results 
support benralizumab $100 \mathrm{mg}$ Q8W as the appropriate dosage for patients with COPD in all future clinical investigations.

Reductions in the rate of severe exacerbations were observed for patients with more frequent prior exacerbations, blood eosinophil counts 300 cells per $\mu \mathrm{L}$ or greater, and post-BD response $15 \%$ or greater. However, the number of severe exacerbations for this subgroup was small, and observed reductions did not reach a nominally statistically significantly difference compared with placebo.

The results obtained for benralizumab treatment for patients with moderate to very severe COPD are similar to those obtained with the anti-interleukin-5 monoclonal antibody mepolizumab. ${ }^{32}$ In the METREX study, the impact of mepolizumab treatment for all patients with COPD, regardless of eosinophilic inflammation, was minimal, but there appeared to be a relationship between baseline blood eosinophil counts and greater treatment effect. Patients with baseline blood eosinophil counts 150 cells per $\mu \mathrm{L}$ or greater had a $14-20 \%$ reduction in annual exacerbations across mepolizumab treatment groups compared with placebo in both the METREX and METREO trials. However, no effect was observed for reduction of severe exacerbations.

The results reported here are for the primary analysis populations in GALATHEA and TERRANOVA who had baseline blood eosinophil counts 220 cells per $\mu \mathrm{L}$ or greater. Our analyses found no evidence of benralizumab treatment effect for patients with blood eosinophil counts less than 220 cells per $\mu \mathrm{L}$. For the identified patient subpopulations demonstrating 
benralizumab treatment effect for exacerbation reduction (three or more exacerbations in the prior year, post-BD $\mathrm{FEV}_{1}<40 \%$ predicted, and post-BD response $\geq 15 \%$ ), treatment effect was observed to increase marginally with increasing baseline blood eosinophil counts. Our findings support the role of blood eosinophil counts as a potential biomarker to help choose specific treatments for patients with COPD.

We did not identify any clinical characteristics or blood eosinophil count thresholds that described patients likely to improve in $\mathrm{FEV}_{1}$ and health status with benralizumab treatment. For the patient group receiving background triple therapy in GALATHEA and TERRANOVA, differences were small between benralizumab and placebo for pre-BD FEV $\mathrm{F}_{1}$ and $\mathrm{HRQOL}$ measures. This finding is similar to studies of other anti-inflammatory therapies for COPD, such as macrolide antibiotics, which demonstrated significant exacerbation reductions but were not associated with significant improvements in change in $\mathrm{FEV}_{1}$ or HRQOL. ${ }^{33}$ The anticipated primary benefit for patients with COPD receiving benralizumab therapy (if benefit is confirmed in a future trial) would likely be prevention or reduction of future exacerbations, a major therapeutic goal for treatment of patients with COPD. ${ }^{1,34}$

\section{Interpretation of novel findings}

Patients with COPD who continue to have frequent exacerbations despite receiving triple inhaled maintenance therapy (ICS/LABA/LAMA) most likely would be an appropriate target patient population for treatment with biologic therapy. Therefore, we used data for those patients to determine benralizumab treatment effect for this specific group of patients with a combination of baseline clinical and physiological factors. We found that a subgroup of patients with COPD 
who had a combination of greater baseline blood eosinophil counts, history of three or more exacerbations, and treatment with triple therapy had greater AER reduction versus placebo with add-on benralizumab $100 \mathrm{mg}$ Q8W treatment compared with the overall population. We did not identify a difference in benralizumab treatment effect for AER reduction for patients with three or more prior exacerbations receiving dual versus triple therapy. However, triple therapy was included in the recommended subgroup because patients should already be receiving maximal (triple) inhaled therapy before biologic treatment is considered. Also, patients should be at continued risk of exacerbations despite maximal treatment with inhaled maintenance therapies before biologic treatment is initiated. Thus, these are the most clinically relevant characteristics. Additional combinations of predictive factors provided further AER reductions, but these additions dramatically reduced population sizes and made interpreting their individual contributions to benralizumab treatment effect problematic.

\section{Limitations}

Our analyses have several potential limitations. These exploratory analyses are hypothesisgenerating only. We evaluated patients with elevated blood eosinophil counts, but our analyses did not study other inflammatory markers and exacerbation phenotypes. Treatment of COPD is also frequently complicated by comorbidities. ${ }^{35}$ The complexity of the patient population may limit our ability to identify a clear treatment effect with any single intervention. The primary studies (GALATHEA and TERRANOVA) were not powered to detect differences within groups for some evaluations. For these analyses, we pooled data from the independent trials to obtain a meaningful number of patients. Combining some identified factors reduced the size of the subgroup considerably, consequently limiting the power of these analyses to confirm an effect 
for these factors. Finally, as with all subgroup analyses, there is the possibility of "regression towards the mean," such that findings for one population may not be replicated or may indicate a magnitude of treatment effect more towards that observed for the overall population when evaluated in a separate data set. As such, it is important to confirm these results in a prospective study. Additional efficacy and safety data are required from all benralizumab studies in COPD before meta-analyses may be effectively conducted, including calculations of number needed to treat to obtain a specified efficacy outcome (e.g., exacerbation rate reduction of XX\%) and number needed to avoid one adverse event (i.e., number needed to harm). However, while these are hypothesis-generating analyses and regression to the mean is a concern, it should be noted that the results were observed in the pooled analysis, as well as in the individual trials, reducing the probability that these results are because of chance alone. It is plausible that these patients with COPD, despite displaying some features observed in asthma, have eosinophilic inflammation that is less responsive to background therapy, including ICS.

\section{Conclusions}

The results of our data analyses of GALATHEA and TERRANOVA suggest that a combination of clinical characteristics and elevated blood eosinophil counts could be used to guide the use of biologic therapies such as benralizumab for a subpopulation of patients with COPD. These findings support a prospective clinical trial of benralizumab $100 \mathrm{mg}$ Q8W for patients with COPD with elevated blood eosinophil counts and a history of frequent exacerbations during treatment with triple inhaled therapy. The RESOLUTE trial (NCT04053634) will evaluate efficacy and safety of benralizumab for this patient population. 


\section{CONTRIBUTORS}

All authors and the funder of this study participated in study design. All authors had access to and analysed and interpreted the data, participated in the development and critical review of the manuscript, approved submission of the manuscript for publication, and are accountable for the accuracy and integrity of the work.

\section{DECLARATION OF INTERESTS}

Gerard J. Criner has received research grants from Actelion, Aeris, AstraZeneca, Boehringer Ingelheim, Chiesi Farmaceutici, CSA Medical, Forest, Gala Therapeutics, Genentech, GlaxoSmithKline, Ikaria, MedImmune, Mereo, Novartis, Pearl, Pulmonx, Respironics, and Spiration PneumRx. He has received equity interest from HGE Health Care Solutions, Inc., and consultation fees from Almirall, AstraZeneca, Boehringer Ingelheim, Chiesi, CSA Medical, Gala Therapeutics, GlaxoSmithKline, Mereo, NGM Bio, Novartis, Nuvaira, Olympus, Pearl, PneumRx, Pulmonx, Respironics, Verona, and Zambon, outside the submitted work. Bartolome R. Celli's division has received grants from AstraZeneca to complete research studies. He has served on an advisory board or as a consultant to Almirall, AstraZeneca, Boehringer Ingelheim GmbH, Chiesi Farmaceutici, GlaxoSmithKline, Menarini, Novartis AG, SA, and Takeda Pharmaceutical Company Limited, outside the submitted work. Dave Singh reports personal fees from Apellis, Cipla, Genentech, Peptinnovate, and Skyepharma; and grants and personal fees from AstraZeneca, Boehringer Ingelheim, Chiesi Farmaceutici, GlaxoSmithKline, Glenmark, Menarini, Merck, Mundipharma, Novartis, Pfizer, Pulmatrix, Teva, Theravance, and Verona. Alvar Agusti reports grants from GlaxoSmithKline, grants and personal fees from AstraZeneca 
and Menarini, and personal fees from Boehringer Ingelheim and Chiesi Farmaceutici outside the submitted work. Alberto Papi is a consultant, advisory board, or board member for AstraZeneca, Boehringer Ingelheim, Chiesi Farmaceutici, GlaxoSmithKline, Mundipharma, Teva, and Zambon. He received lecture fees from Almirall, AstraZeneca, Boehringer Ingelheim, Chiesi Farmaceutici, GlaxoSmithKline, Mundipharma, Novartis, and Teva. He reports industrysponsored grants from AstraZeneca, Boehringer Ingelheim, Chiesi Farmaceutici, Fondazione Maugeri, Fondazione Chiesi Farmaceutici, GlaxoSmithKline, and Menarini, outside the submitted work. Maria Jison, Natalya Makulova, Vivian H. Shih, Laura Brooks, Peter Barker, Ubaldo J. Martin, and Paul Newbold are employees of AstraZeneca.

\section{ACKNOWLEDGMENTS}

The GALATHEA and TERRANOVA trials were sponsored by AstraZeneca (GALATHEA and TERRANOVA) and Kyowa Hakko Kirin (GALATHEA). These analyses were sponsored by AstraZeneca. Dave Singh is supported by the NIHR Manchester BRC. We thank the investigators, health care providers, research staff, and patients who participated in the GALATHEA and TERRANOVA clinical trials. Writing and editing assistance, including preparation of a draft manuscript under direction and guidance of the authors, incorporating author feedback, and manuscript submission, was provided by Debra Scates, $\mathrm{PhD}$, of JK Associates, Inc., and Michael A. Nissen, ELS, of AstraZeneca. This support was funded by AstraZeneca. 


\section{DATA-SHARING STATEMENT}

Data underlying the findings described in this manuscript may be requested in accordance with AstraZeneca's data-sharing policy described at https://astrazenecagroupdt.pharmacm.com/DT/Home. 


\section{REFERENCES}

1 Singh D, Agusti A, Anzueto A, et al. Global strategy for the diagnosis, management, and prevention of chronic obstructive lung disease: the GOLD science committee report 2019. Eur Respir J 2019; 53: pii: 1900164.

2 Müllerová H, Meeraus WH, Galkin DV, Albers FC, Landis SH. Clinical burden of illness among patients with severe eosinophilic COPD. Int J Chron Obstruct Pulmon Dis 2019; 14: $741-55$.

3 Vestbo J, Papi A, Corradi M, et al. Single inhaler extrafine triple therapy versus longacting muscarinic antagonist therapy for chronic obstructive pulmonary disease (TRINITY): a double-blind, parallel group, randomised controlled trial. Lancet 2017; 389: 1919-29.

4 Barnes PJ. Inflammatory mechanisms in patients with chronic obstructive pulmonary disease. J Allergy Clin Immunol 2016; 138: 16-27.

5 Yun JH, Lamb A, Chase R, et al. Blood eosinophil count thresholds and exacerbations in patients with chronic obstructive pulmonary disease. J Allergy Clin Immunol 2018; 141: $2037-47$.

6 Saha S, Brightling CE. Eosinophilic airway inflammation in COPD. Int J Chron Obstruct Pulmon Dis 2006; 1: 39-47.

7 George L, Brightling CE. Eosinophilic airway inflammation: role in asthma and chronic obstructive pulmonary disease. Ther Adv Chronic Dis 2016; 7: 34-51.

8 Singh D, Kolsum U, Brightling CE, et al. Eosinophilic inflammation in COPD: prevalence and clinical characteristics. Eur Respir J 2014; 44: 1697-700. 
9 Brightling CE, Monterio W, Ward R, et al. Sputum eosinophilia and short-term response to prednisolone in chronic obstructive pulmonary disease: a randomised controlled trial. Lancet 2000; 356: 1480-85.

10 Brightling CE, McKenna S, Hargadon B, et al. Sputum eosinophilia and the short term response to inhaled mometasone in chronic obstructive pulmonary disease. Thorax 2005; 60: 193-8.

11 Pizzichini E, Pizzichini MM, Gibson P, et al. Sputum eosinophilia predicts benefit from prednisone in smokers with chronic obstructive bronchitis. Am J Respir Crit Care Med 1998; 158: 1511-7.

12 Leigh R, Pizzichini MM, Morris MM, Maltais F, Hargreave FE, Pizzichini E. Stable COPD: predicting benefit from high-dose inhaled corticosteroid treatment. Eur Respir J 2006; 27: 964-71.

13 Hastie AT, Martinez FJ, Curtis JL, et al. Association of sputum and blood eosinophil concentrations with clinical measures of COPD severity: an analysis of the SPIROMICS cohort. Lancet Respir Med 2017; 5: 956-67.

14 Kolsum U, Damera G, Pham TH, et al. Pulmonary inflammation in patients with chronic obstructive pulmonary disease with higher blood eosinophil counts. J Allergy Clin Immunol 2017; 140: 1181-4.

15 Eltboli O, Mistry V, Barker B, Brightling CE. Relationship between blood and bronchial submucosal eosinophilia and reticular basement membrane thickening in chronic obstructive pulmonary disease. Respirology 2015; 20: 667-70. 
16 Bafadhel M, McKenna S, Terry S, et al. Blood eosinophils to direct corticosteroid treatment of exacerbations of chronic obstructive pulmonary disease: a randomized placebo-controlled trial. Am J Respir Crit Care Med 2012; 186: 48-55.

17 Negewo NA, McDonald VM, Baines KJ, et al. Peripheral blood eosinophils: a surrogate marker for airway eosinophilia in stable COPD. Int J Chron Obstruct Pulmon Dis 2016; 11: $1495-504$.

18 Criner GJ, Martinez FJ, Aaron S, et al. Current controversies in chronic obstructive pulmonary disease. A report from the Global Initiative for Chronic Obstructive Lung Disease scientific committee. Ann Am Thorac Soc 2019; 16: 29-39.

19 Bafadhel M, McKenna S, Terry S, et al. Acute exacerbations of chronic obstructive pulmonary disease: identification of biologic clusters and their biomarkers. Am J Respir Crit Care Med 2011; 184: 662-71.

20 Pascoe S, Locantore N, Dransfield MT, Barnes NC, Pavord ID. Blood eosinophil counts, exacerbations, and response to the addition of inhaled fluticasone furoate to vilanterol in patients with chronic obstructive pulmonary disease: a secondary analysis of data from two parallel randomised controlled trials. Lancet Respir Med 2015; 3: 435-42.

21 Watz H, Tetzlaff K, Wouters EF, et al. Blood eosinophil count and exacerbations in severe chronic obstructive pulmonary disease after withdrawal of inhaled corticosteroids: a post-hoc analysis of the WISDOM trial. Lancet Respir Med 2016; 4: 390-8.

22 Kerkhof M, Sonnappa S, Postma DS, et al. Blood eosinophil count and exacerbation risk in patients with COPD. Eur Respir J 2017; 50: 1700761.

23 Pavord ID, Lettis S, Locantore N, et al. Blood eosinophils and inhaled corticosteroid/long-acting $\beta$-2 agonist efficacy in COPD. Thorax 2016; 71: 118-25. 
24 Siddiqui SH, Guasconi A, Vestbo J, et al. Blood eosinophils: a biomarker of response to extrafine beclomethasone/formoterol in chronic obstructive pulmonary disease. Am J Respir Crit Care Med 2015; 192: 523-5.

25 AstraZeneca. Fasenra (benralizumab) prescribing information. November, 2017. https://www.azpicentral.com/fasenra/fasenra_pi.pdf\#page=1 (accessed July 9 2019).

26 AstraZeneca. Fasenra (benralizumab) summary of product characteristics. 2018. http://ec.europa.eu/health/documents/communityregister/2018/20180108139598/anx_139598_en.pdf (accessed July 9 2019).

27 Bleecker ER, FitzGerald JM, Chanez P, et al. Efficacy and safety of benralizumab for patients with severe asthma uncontrolled with high-dosage inhaled corticosteroids and long-acting beta2-agonists (SIROCCO): a randomised, multicentre, placebo-controlled phase 3 trial. Lancet 2016; 388: 2115-27.

28 FitzGerald JM, Bleecker ER, Nair P, et al. Benralizumab, an anti-interleukin-5 receptor alpha monoclonal antibody, as add-on treatment for patients with severe, uncontrolled, eosinophilic asthma (CALIMA): a randomised, double-blind, placebo-controlled phase 3 trial. Lancet 2016; 388: 2128-41.

29 O’Quinn S, Xu X, Hirsch I. Daily patient-reported health status assessment improvements with benralizumab for patients with severe, uncontrolled eosinophilic asthma. J Asthma Allergy 2019; 12: 21-33.

30 Kolbeck R, Kozhich A, Koike M, et al. MEDI-563, a humanized anti-IL-5 receptor alpha mAb with enhanced antibody-dependent cell-mediated cytotoxicity function. J Allergy Clin Immunol 2010; 125: 1344-53. 
31 Criner GJ, Celli BR, Brightling CE, et al. Benralizumab for the prevention of COPD exacerbations. N Engl J Med 2019; 381: 1023-34.

32 Pavord ID, Chanez P, Criner GJ, et al. Mepolizumab for eosinophilic chronic obstructive pulmonary disease. $N$ Engl J Med 2017; 377: 1613-29.

33 Herath SC, Poole P. Prophylactic antibiotic therapy for chronic obstructive pulmonary disease (COPD). Cochrane Database Syst Rev 2018; 10: CD009764.

34 Viniol C, Vogelmeier CF. Exacerbations of COPD. Eur Respir Rev 2018; 27: 170103.

35 Singh D, Martin M. Biologics for chronic obstructive pulmonary disease: present and future. BRN Reviews 2018; 4: 34-52. 
Table 1: Explanatory variable factors used for each structured analysis run

\begin{tabular}{|c|c|c|c|}
\hline Variable & Run 1 & Run 2 & Run 3 \\
\hline Post-BD FEV ${ }_{1} \%$ PN & Yes & Yes & No \\
\hline Post-BD FEVC \% PN & Yes & Yes & No \\
\hline Post-BD FEV $1 / F V C$ & No & No & Yes \\
\hline Percentage reversibility & No & No & Yes \\
\hline Sex & Yes & Yes & Yes \\
\hline Age & Yes & Yes & Yes \\
\hline Race & Yes & Yes & Yes \\
\hline Country & No & Yes & No \\
\hline Baseline blood eosinophil count & Yes & Yes & Yes \\
\hline COPD medication & Yes & Yes & Yes \\
\hline Number of prior exacerbations* & Yes & Yes & Yes \\
\hline Number of prior severe exacerbations* & Yes & Yes & Yes \\
\hline Concurrent asthma & Yes & Yes & Yes \\
\hline History of asthma & Yes & Yes & Yes \\
\hline COTE index & Yes & Yes & Yes \\
\hline Nicotine use status & Yes & No & No \\
\hline Nicotine consumption & No & Yes & Yes \\
\hline CAT total score & Yes & Yes & Yes \\
\hline Diagnosis of rhinitis & Yes & Yes & Yes \\
\hline Diagnosis of OCB & Yes & Yes & Yes \\
\hline Diagnosis of emphysema & Yes & Yes & Yes \\
\hline Time since COPD diagnosis & Yes & Yes & Yes \\
\hline
\end{tabular}

$\mathrm{BD}=$ bronchodilator. $\mathrm{CAT}=\mathrm{COPD}$ Assessment Test. $\mathrm{COTE}=\mathrm{COPD}$-specific comorbidity test.

$\mathrm{FEV}_{1}=$ forced expiratory volume in 1 second. $\mathrm{FEVC}=$ forced expiratory vital capacity.

$\mathrm{FVC}=$ forced vital capacity. $\mathrm{OCB}=$ oxygen cost of breathing. $\mathrm{PN}=$ predicted normal. 
*In the past year.

Nicotine use status refers to categorisation of patients as current smokers, former smokers, or non-smokers. Nicotine consumption refers to the amount of nicotine consumed by the patient (pack-years). 
Table 2: Key baseline characteristics of overall GALATHEA/TERRANOVA pooled population and those meeting criteria for responders

\begin{tabular}{|c|c|c|c|}
\hline & & & $\begin{array}{l}\text { Patients with blood } \\
\text { eosinophil counts } \geq 220 \text { cells }\end{array}$ \\
\hline & & $\begin{array}{l}\text { Patients with blood } \\
\text { eosinophil counts }\end{array}$ & $\begin{array}{l}\text { per } \mu \mathrm{L} \\
\geq 3 \text { prior exacerbations, }\end{array}$ \\
\hline Baseline characteristic & $\begin{array}{l}\text { Full analysis set } \\
(\mathrm{N}=\mathbf{3 , 9 1 0})\end{array}$ & $\begin{array}{l}\geq 220 \text { cells per } \mu L \\
(n=2,665)\end{array}$ & $\begin{array}{l}\text { receiving triple therapy } \\
(n=515)\end{array}$ \\
\hline Age, mean years $(\mathrm{SD})$ & $65 \cdot 3(8 \cdot 3)$ & $65 \cdot 4(8 \cdot 3)$ & $66 \cdot 1(8 \cdot 0)$ \\
\hline Female, n (\%) & $1,333(34)$ & $849(32)$ & $164(32)$ \\
\hline \multicolumn{4}{|l|}{ Nicotine use history, n (\%) } \\
\hline Current & $1,253(32)$ & $826(31)$ & $140(27)$ \\
\hline Former & $2,657(68)$ & $1,839(69)$ & $375(73)$ \\
\hline $\begin{array}{l}\text { Median time since COPD } \\
\text { diagnosis, years (IQR) }\end{array}$ & $7 \cdot 0(4 \cdot 0$ to $11 \cdot 3)$ & $6 \cdot 9(4 \cdot 0$ to $11 \cdot 1)$ & $7 \cdot 7(4 \cdot 3$ to $12 \cdot 4)$ \\
\hline \multicolumn{4}{|l|}{ Exacerbations in prior year } \\
\hline Mean (SD) & $2 \cdot 3(1 \cdot 1)$ & $2 \cdot 3(1 \cdot 1)$ & $3 \cdot 8(1.3)$ \\
\hline$\geq 3, \mathrm{n}(\%)$ & $1,016(26)$ & $701(26)$ & $515(100)$ \\
\hline 1 severe, $\mathrm{n}(\%)$ & $1,111(28)$ & $734(28)$ & $111(22)$ \\
\hline$\geq 1$ severe, $\mathrm{n}(\%)$ & $1,456(37)$ & $976(37)$ & $198(38)$ \\
\hline \multicolumn{4}{|l|}{ Region, n (\%) } \\
\hline Asia & $393(10)$ & $292(11)$ & $58(11)$ \\
\hline Eastern Europe & $1,141(29)$ & $788(30)$ & $87(17)$ \\
\hline Europe & $687(18)$ & $450(17)$ & $150(29)$ \\
\hline North America & $1,028(26)$ & $692(26)$ & $145(28)$ \\
\hline
\end{tabular}




\begin{tabular}{|c|c|c|c|}
\hline ROW & $661(17)$ & $443(17)$ & $75(15)$ \\
\hline \multicolumn{4}{|l|}{ Maintenance COPD } \\
\hline \multicolumn{4}{|l|}{ medications, $\mathrm{n}(\%)$} \\
\hline ICS/LABA & $1,083(28)$ & $764(29)$ & $0(0)$ \\
\hline LABA/LAMA & $298(8)$ & $215(8)$ & $0(0)$ \\
\hline ICS/LABA/LAMA & $2,529(65)$ & $1,686(63)$ & $515(100)$ \\
\hline \multicolumn{4}{|l|}{ Mean $\mathrm{FEV}_{1}$ : } \\
\hline Pre-BD, \% PN (SD) & $39 \cdot 9(13 \cdot 2)$ & $40 \cdot 9(13 \cdot 5)$ & $37 \cdot 7(13 \cdot 0)$ \\
\hline Post-BD, \% PN (SD) & $42 \cdot 2(12 \cdot 0)$ & $43 \cdot 0(12 \cdot 0)$ & $40 \cdot 3(12 \cdot 2)$ \\
\hline \multicolumn{4}{|l|}{ Mean $\mathrm{FEV}_{1} / \mathrm{FVC}$ : } \\
\hline Post-BD, \% (SD) & $43(11)$ & $44(11)$ & $41(11)$ \\
\hline Reversibility, \% (SD) & $10 \cdot 1(13 \cdot 8)$ & $9 \cdot 9(14 \cdot 2)$ & $11 \cdot 7(13 \cdot 5)$ \\
\hline \multicolumn{4}{|l|}{ Baseline blood eosinophil } \\
\hline \multicolumn{4}{|l|}{ count } \\
\hline $\begin{array}{l}\text { Median cells per } \mu \mathrm{L} \\
\text { (IQR) }\end{array}$ & $300(170$ to 440$)$ & $380(290$ to 540$)$ & $380(290$ to 550$)$ \\
\hline$\geq 300$ cells per $\mu \mathrm{L}, \mathrm{n}(\%)$ & $1,990(51)$ & $1,990(75)$ & $377(73)$ \\
\hline SGRQ mean total score (SD) & $52 \cdot 6(17 \cdot 4)$ & $52 \cdot 2(17 \cdot 4)$ & $55 \cdot 5(16 \cdot 3)$ \\
\hline CAT mean total score (SD) & $20 \cdot 1(7 \cdot 0)$ & $20 \cdot 1(7 \cdot 0)$ & $21 \cdot 1(6 \cdot 9)$ \\
\hline \multicolumn{4}{|l|}{ Asthma diagnosis, n (\%) } \\
\hline Current & $145(4)$ & $112(4)$ & $33(6)$ \\
\hline Previous & $266(7)$ & $188(7)$ & $53(10)$ \\
\hline Emphysema diagnosis, n (\%) & $2,155(55)$ & $1,452(55)$ & $303(59)$ \\
\hline
\end{tabular}




\begin{tabular}{llll}
\hline Chronic bronchitis, $\mathrm{n}(\%)$ & $2,731(70)$ & $1,862(70)$ & $371(72)$
\end{tabular}

\begin{tabular}{llll}
\hline Atopic status, $\mathrm{n}(\%)$ & $1,261(32)$ & $952(36)$ & $174(34)$
\end{tabular}

$\mathrm{BD}=$ bronchodilator. $\mathrm{CAT}=\mathrm{COPD}$ Assessment Test. $\mathrm{FEV}_{1}=$ forced expiratory volume in 1 second. $\mathrm{FVC}=$ forced vital capacity. ICS=inhaled corticosteroids. IQR=interquartile range. LABA=long-acting $\beta_{2}$-agonists. LAMA=long-acting muscarinic antagonists. $\mathrm{PN}=$ predicted normal. ROW=rest of world. SGRQ=St. George's Respiratory Questionnaire. 
Table 3: Annual exacerbation rate and rate reduction for patient subgroups with frequent versus less frequent exacerbations, receiving dual or triple therapy, and by baseline lung function (pooled GALATHEA/TERRANOVA patients with baseline blood eosinophil counts 220 cells per $\mu \mathrm{L}$ or greater)

\begin{tabular}{|c|c|c|c|}
\hline & Benralizumab 30 mg Q8W & $\begin{array}{l}\text { Benralizumab } 100 \mathrm{mg} \\
\text { Q8W }\end{array}$ & Placebo \\
\hline \multicolumn{4}{|c|}{$\leq 2$ prior exacerbations,* AER (RR vs placebo; $95 \%$ CI) [n] } \\
\hline Post-BD FEV ${ }_{1}<40 \%$ & $\begin{array}{l}1 \cdot 24(0 \cdot 90 ; 0 \cdot 68 \text { to } 1 \cdot 18) \\
{[152]}\end{array}$ & $\begin{array}{l}1 \cdot 23(0 \cdot 89 ; 0 \cdot 68 \text { to } 1 \cdot 17) \\
{[158]}\end{array}$ & $\begin{array}{l}1 \cdot 39 \\
{[127]}\end{array}$ \\
\hline Post-BD FEV ${ }_{1} \geq 40 \%$ & $\begin{array}{l}0 \cdot 96(1 \cdot 13 ; 0 \cdot 86 \text { to } 1 \cdot 47) \\
{[198]}\end{array}$ & $\begin{array}{l}0 \cdot 73(0 \cdot 86 ; 0 \cdot 65 \text { to } 1 \cdot 14) \\
{[189]}\end{array}$ & $\begin{array}{l}0 \cdot 85 \\
{[195]}\end{array}$ \\
\hline Post-BD response $<15 \%$ & $\begin{array}{l}1 \cdot 07(1 \cdot 08 ; 0 \cdot 85 \text { to } 1 \cdot 38) \\
{[231]}\end{array}$ & $\begin{array}{l}1 \cdot 01(1 \cdot 02 ; 0 \cdot 81 \text { to } 1 \cdot 29) \\
{[243]}\end{array}$ & $\begin{array}{l}0 \cdot 99 \\
{[234]}\end{array}$ \\
\hline Post-BD response $\geq 15 \%$ & $\begin{array}{l}1 \cdot 08(0 \cdot 81 ; 0 \cdot 58 \text { to } 1 \cdot 12) \\
{[117]}\end{array}$ & $\begin{array}{l}0 \cdot 80(0 \cdot 60 ; 0 \cdot 42 \text { to } 0 \cdot 85) \\
{[103]}\end{array}$ & $\begin{array}{l}1 \cdot 34 \\
{[87]}\end{array}$ \\
\hline$\geq 3$ prior exacerbations, $*$ & $(\mathrm{RR} v s$ placebo; $95 \% \mathrm{CI})[\mathrm{n}$ & & \\
\hline Post-BD FEV ${ }_{1}<40 \%$ & $\begin{array}{l}2 \cdot 33(0 \cdot 98 ; 0 \cdot 74 \text { to } 1 \cdot 30) \\
{[81]}\end{array}$ & $\begin{array}{l}1 \cdot 54(0 \cdot 65 ; 0 \cdot 48 \text { to } 0 \cdot 88) \\
{[72]}\end{array}$ & $\begin{array}{l}2 \cdot 38 \\
{[80]}\end{array}$ \\
\hline Post-BD FEV $\mathrm{F}_{1} \geq 40 \%$ & $\begin{array}{l}1 \cdot 77(0 \cdot 94 ; 0 \cdot 65 \text { to } 1 \cdot 36) \\
{[69]}\end{array}$ & $\begin{array}{l}1.40(0 \cdot 74 ; 0.52 \text { to } 1 \cdot 06) \\
{[79]}\end{array}$ & $\begin{array}{l}1 \cdot 89 \\
{[69]}\end{array}$ \\
\hline Post-BD response $<15 \%$ & $\begin{array}{l}2 \cdot 06(1 \cdot 11 ; 0 \cdot 83 \text { to } 1 \cdot 49) \\
{[98]}\end{array}$ & $\begin{array}{l}1.49(0 \cdot 80 ; 0.59 \text { to } 1.08) \\
{[100]}\end{array}$ & $\begin{array}{l}1 \cdot 86 \\
{[97]}\end{array}$ \\
\hline Post-BD response $\geq 15 \%$ & $2.07(0.82 ; 0.58$ to $1 \cdot 15)$ & $1.49(0.59 ; 0.41$ to 0.84$)$ & $2 \cdot 54$ \\
\hline
\end{tabular}




\section{Post-BD response $<15 \%$ and receiving triple therapy, AER (RR vs placebo; 95\% CI) [n]}

\begin{tabular}{llll}
\hline Post-BD FEV $_{1}<40 \%$ & $1.59(1.04 ; 0.81$ to 1.34$)$ & $1.45(0.95 ; 0.74$ to 1.22$)$ & 1.53 \\
& {$[155]$} & {$[163]$} & {$[143]$} \\
\hline Post-BD FEV $_{1} \geq 40 \%$ & $1.15(1.18 ; 0.89$ to 1.55$)$ & $0.91(0.92 ; 0.70$ to 1.22$)$ & 0.99 \\
& {$[174]$} & {$[180]$} & {$[188]$} \\
\hline
\end{tabular}

Post-BD response $\geq 15 \%$ and receiving triple therapy, AER (RR $v$ s placebo; 95\% CI) [n]

\begin{tabular}{llll}
\hline Post-BD FEV $_{1}<40 \%$ & $1.68(0.75 ; 0.55$ to 1.03$)$ & $1.02(0.46 ; 0.32$ to 0.66$)$ & $2 \cdot 24$ \\
& {$[76]$} & {$[67]$} & {$[63]$} \\
\hline Post-BD FEV $_{1} \geq 40 \%$ & $1.28(0.99 ; 0.70$ to 1.39$)$ & $0.97(0.75 ; 0.52$ to 1.07$)$ & 1.30 \\
& {$[93]$} & {$[87]$} & {$[75]$} \\
\hline
\end{tabular}

$\leq 2$ prior exacerbations, ${ }^{*}$ AER $(\mathrm{RR}$ vs placebo; 95\% CI) [n]

\begin{tabular}{llll}
\hline Dual therapy & $\begin{array}{l}0.76(1.19 ; 0.90 \text { to } 1.58) \\
{[221]}\end{array}$ & $\begin{array}{l}0.81(1.26 ; 0.94 \text { to } 1.67) \\
{[209]}\end{array}$ & $\begin{array}{l}0.64 \\
{[222]}\end{array}$ \\
\hline Triple therapy & $\begin{array}{l}1.08(1.00 ; 0.82 \text { to } 1.21) \\
{[350]}\end{array}$ & $\begin{array}{l}0.95(0.88 ; 0.73 \text { to } 1.08) \\
{[348]}\end{array}$ & $\begin{array}{l}1.08 \\
{[322]}\end{array}$ \\
\hline Prior severe exacerbation* & $\begin{array}{l}1.07(1.06 ; 0.84 \text { to } 1.35) \\
{[220]}\end{array}$ & $\begin{array}{l}1.02(1.02 ; 0.80 \text { to } 1.30) \\
{[217]}\end{array}$ & $\begin{array}{l}1.01 \\
{[194]}\end{array}$ \\
\hline $\begin{array}{l}\text { No prior severe } \\
\text { exacerbation* }\end{array}$ & $\begin{array}{l}0.90(1.10 ; 0.89 \text { to } 1.35) \\
{[351]}\end{array}$ & $\begin{array}{l}0.82(0.99 ; 0.80 \text { to } 1.23) \\
{[340]}\end{array}$ & $\begin{array}{l}0.82 \\
{[350]}\end{array}$ \\
\hline
\end{tabular}

$\geq 3$ prior exacerbations, ${ }^{*}$ AER $(\mathrm{RR} v s$ placebo; 95\% CI $)[\mathrm{n}]$

\begin{tabular}{llll}
\hline Dual therapy & $\begin{array}{l}1 \cdot 14(0.53 ; 0.36 \text { to } 0.78) \\
{[55]}\end{array}$ & $\begin{array}{l}1.30(0.60 ; 0.42 \text { to } 0 \cdot 87) \\
{[57]}\end{array}$ & $\begin{array}{l}2 \cdot 15 \\
{[54]}\end{array}$ \\
\hline Triple therapy & $\begin{array}{l}2 \cdot 09(0.99 ; 0.79 \text { to } 1.23) \\
{[150]}\end{array}$ & $\begin{array}{l}1.49(0.70 ; 0.56 \text { to } 0.88) \\
{[151]}\end{array}$ & $\begin{array}{l}2 \cdot 12 \\
{[149]}\end{array}$ \\
\hline Prior severe exacerbation* & $1.98(0.87 ; 0.63$ to 1.19$)$ & $1 \cdot 35(0.59 ; 0.42$ to $0 \cdot 82)$ & $2 \cdot 29$ \\
\hline
\end{tabular}




\begin{tabular}{llll}
\hline No prior severe & $1.68(0.82 ; 0.64$ to 1.05$)$ & $1.51(0.74 ; 0.58$ to 0.94$)$ & 2.05 \\
exacerbation* & {$[131]$} & {$[132]$} & {$[120]$}
\end{tabular}

$\mathrm{AER}=$ annual exacerbation rate. $\mathrm{BD}=$ bronchodilator. $\mathrm{FEV}_{1}=$ forced expiratory volume in 1 second. Q8W=every 8 weeks (first three doses every 4 weeks). RR=rate ratio.

*In the past year. 
FIGURE LEGENDS

Figure 1: Structured exploration of data from a) GALATHEA and b) TERRANOVA separately and c) GALATHEA/TERRANOVA pooled data for patients with baseline blood eosinophil counts 220 cells per $\mu \mathrm{L}$ or greater

$\mathrm{BD}=$ bronchodilator. $\mathrm{CAT}=\mathrm{COPD}$ Assessment Test. COTE$=\mathrm{COPD}$-specific comorbidity test. $\mathrm{FEV}_{1}=$ forced expiratory volume in 1 second. $\mathrm{FEVC}=$ forced expiratory vital capacity.

$\mathrm{OCB}=$ oxygen cost of breathing. $\mathrm{PN}=$ predicted normal. Q8W=every 8 weeks (first three doses every 4 weeks).

Post-BD response was included in Run 3 and was found to be greatly associated with treatment response. Prior exacerbations are exacerbations in the year before study entry.

Figure 2: Effects of baseline a) post-BD $\mathrm{FEV}_{1}(\% \mathrm{PN})$, b) post-BD response, and c) clinically defined reversibility on reduction of annual exacerbation rate with benralizumab versus placebo for patients with baseline blood eosinophil counts 220 cells per $\mu \mathrm{L}$ or greater

$\mathrm{BD}=$ bronchodilator. $\mathrm{FEV}_{1}=$ forced expiratory volume in 1 second $\mathrm{NC}=$ not calculated. PN=predicted normal. Q8W=every 8 weeks (first three doses every 4 weeks). 
Figure 3: Effects of benralizumab treatment on annual exacerbation rate for patients with baseline blood eosinophil counts 220 cells per $\mu \mathrm{L}$ or greater by identified individual predictors of response

$\mathrm{BD}=$ bronchodilator. $\mathrm{FEV}_{1}=$ forced expiratory volume in 1 second. $\mathrm{PN}=$ predicted normal. Q8W=every 8 weeks (first three doses every 4 weeks).

*Combination of two or three of the following: inhaled corticosteroids, long-acting $\beta_{2}$-agonists, and long-acting muscarinic antagonists.

Prior exacerbations are exacerbations in the year before study entry.

Figure 4: Pooled data for benralizumab treatment effect versus placebo on annual exacerbation rate for patients with baseline blood eosinophil counts 220 cells per $\mu \mathrm{L}$ or greater and less than 220 cells per $\mu \mathrm{L}$ by identified individual predictors of response

$\mathrm{BD}=$ bronchodilator. $\mathrm{FEV}_{1}=$ forced expiratory volume in 1 second. $\mathrm{Q} 8 \mathrm{~W}=$ every 8 weeks (first three doses every 4 weeks).

Prior exacerbations are exacerbations in the year before study entry.

Methodology used for the generation of data in these plots was different from other exploratory analyses, leading to some differences in values for some data points. 
Figure 5: Effects of baseline blood eosinophil count on annual exacerbation rate in pooled data set

Q8W=every 8 weeks (first three doses every 4 weeks).

Figure 6: Impact of combining predictors on placebo exacerbation rate and benralizumab $100 \mathrm{mg}$ Q8W treatment effect size

$\mathrm{BD}=$ bronchodilator. $\mathrm{ERR}=$ exacerbation rate reduction. $\mathrm{FEV}_{1}=$ forced expiratory volume in 1 second. Q8W=every 8 weeks (first three doses every 4 weeks).

Prior exacerbations are exacerbations in the year before study entry. 


\section{Benralizumab $30 \mathrm{mg}$ Q8W vs placebo}

Number of prior exacerbations

Post-BD FEV $1 \%$ PN

Time since diagnosis

Baseline blood eosinophil count

Post-BD FVC \% PN

History of asthma

CAT total score

Sex

Diagnosis of rhinitis

Age

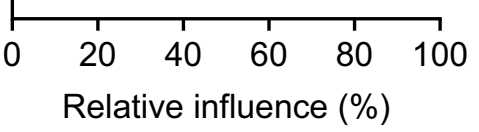

Benralizumab $30 \mathrm{mg}$ Q8W vs placebo

Number of prior exacerbations

Post-BD FEV $1 \%$ PN

Post-BD FVC \% PN

CAT total score

Time since diagnosis

Sex

Age

Concurrent asthma

Baseline blood eosinophil count

COTE index

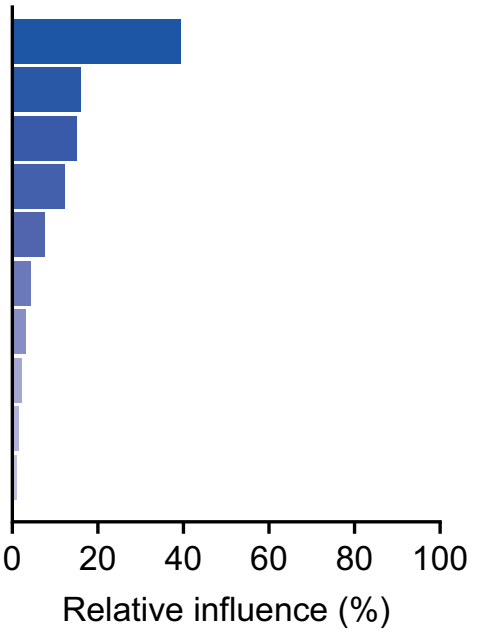

\section{Benralizumab $30 \mathrm{mg}$ Q8W vs placebo}

Number of prior exacerbations

Post-BD FEV $1 \%$ PN

Post-BD FVC \% PN

Time since diagnosis

Concurrent asthma

History of asthma

CAT total score

Baseline blood eosinophil count

Age

Diagnosis of OCB

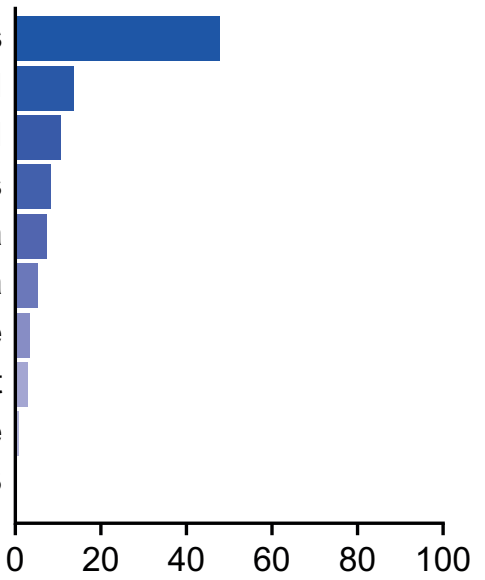

Relative influence (\%)

\section{Benralizumab $100 \mathrm{mg}$ Q8W vs placebo}

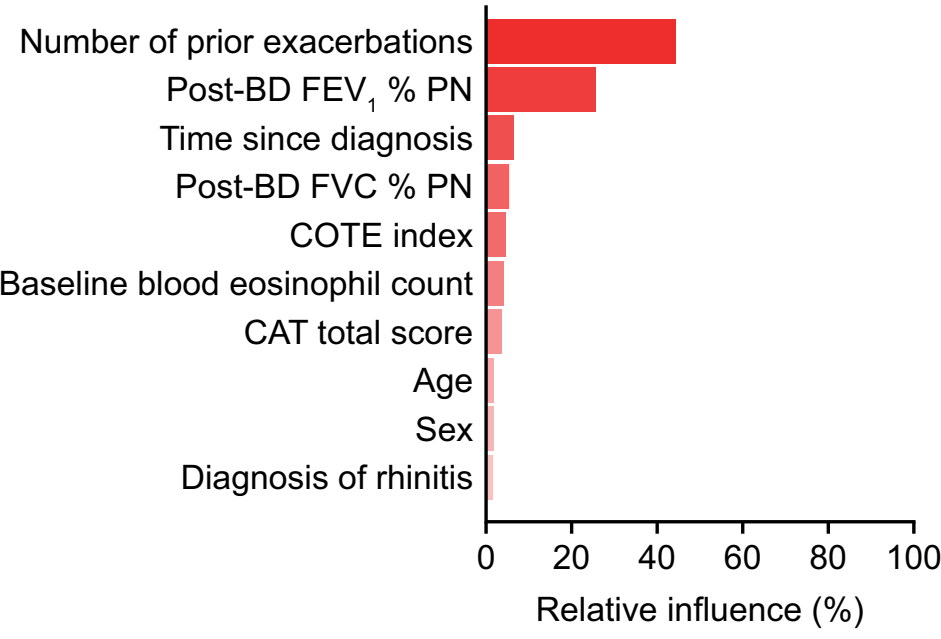

\section{Benralizumab $100 \mathrm{mg} \mathrm{Q8W}$ vs placebo}

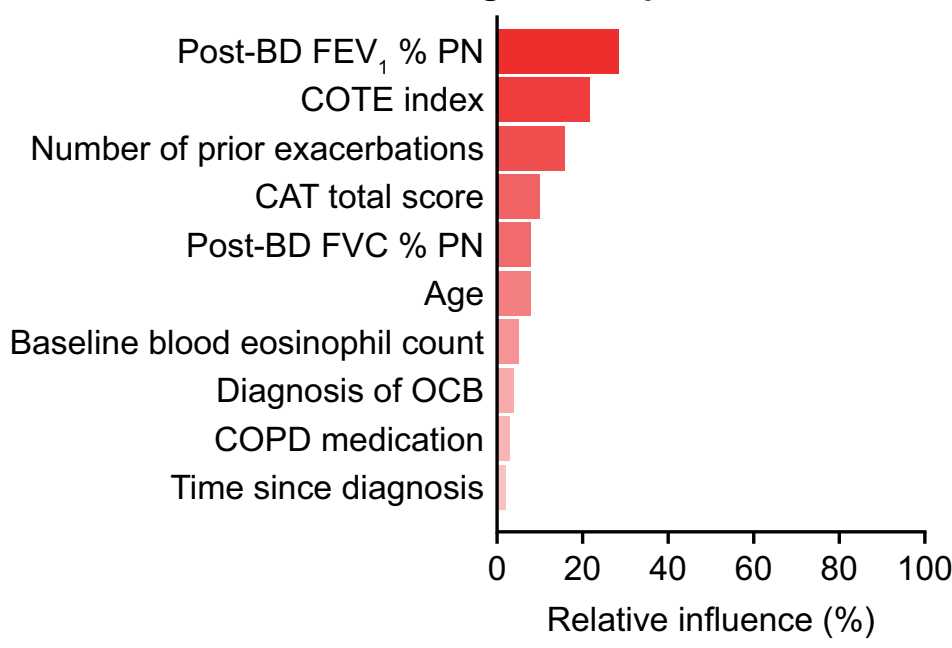

\section{Benralizumab $100 \mathrm{mg}$ Q8W vs placebo}

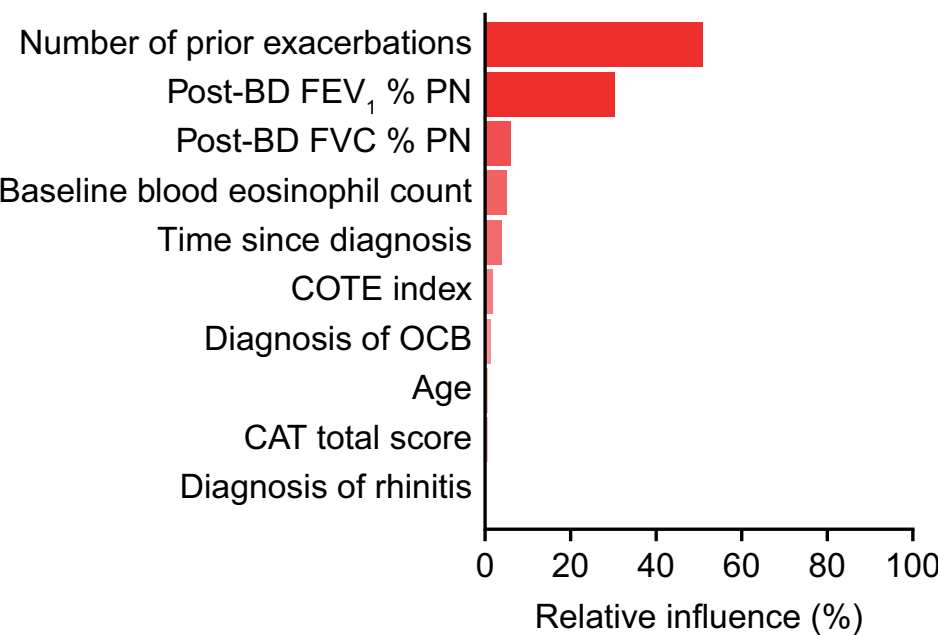


GALATHEA ( $\geq 220$ cells per $\mu \mathrm{L}$ )

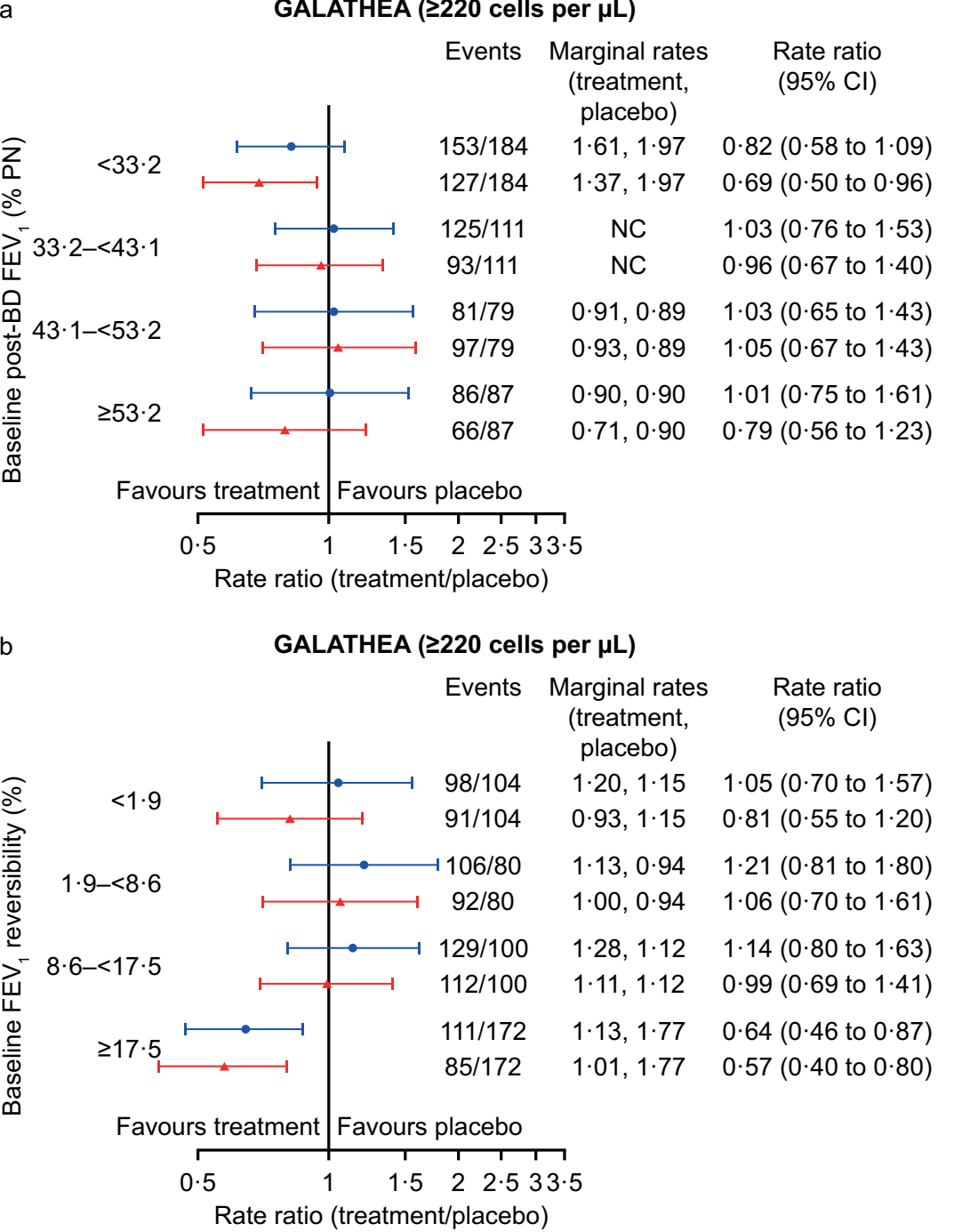

GALATHEA ( $\geq 220$ cells per $\boldsymbol{\mu L}$ )

\begin{tabular}{|c|c|c|c|c|}
\hline \multirow{3}{*}{$\begin{array}{r}\text { Reversible } \\
(>12 \% \text { and } 200-m L \\
\left.\text { increase in } \mathrm{FEV}_{1}\right) \\
19 \%\end{array}$} & & \multicolumn{2}{|r|}{$\begin{array}{l}\text { (treatment, } \\
\text { placebo) }\end{array}$} & (95\% Cl) \\
\hline & $\longmapsto$ & $\longrightarrow$ & $0 \cdot 83,1 \cdot 31$ & $0.79(0.51$ to 1.22$)$ \\
\hline & & & $1 \cdot 03,1 \cdot 31$ & $0.64(0.41$ to 1.00$)$ \\
\hline Not reversible & 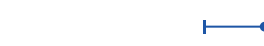 & 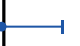 & $1 \cdot 22,1 \cdot 23$ & $1.00(0.82$ to 1.22$)$ \\
\hline $81 \%$ & & -1 & $1 \cdot 08,1 \cdot 23$ & $0.88(0.72$ to 1.08$)$ \\
\hline $\begin{array}{r}\text { Post-BD } \\
\text { response } \geq 15 \%\end{array}$ & & & $1 \cdot 21,1 \cdot 61$ & $0.75(0.57$ to 0.99$)$ \\
\hline $31 \%$ & $\longrightarrow$ & & $1 \cdot 01,1 \cdot 61$ & $0.63(0.46$ to 0.85$)$ \\
\hline $\begin{array}{r}\text { Post-BD } \\
\text { response }<15 \%\end{array}$ & r & & $-1 \cdot 17,1 \cdot 06$ & $1.10(0.87$ to 1.40$)$ \\
\hline $69 \%$ & & $\longrightarrow$ & $1 \cdot 03,1.06$ & $0.97(0.77$ to 1.23$)$ \\
\hline $\begin{array}{r}\text { st-BD response } \\
\geq 15 \% \text { AND: }\end{array}$ & & & & \\
\hline Reversible & & $\longrightarrow$ & $1 \cdot 01,1 \cdot 38$ & $0.73(0.47$ to 1.14$)$ \\
\hline & & & $0 \cdot 84,1 \cdot 38$ & $0.61(0.38$ to 0.97$)$ \\
\hline Not reversible & & $\longrightarrow$ & $1 \cdot 58,1.98$ & $0.80(0.56$ to 1.15$)$ \\
\hline & . & & $1 \cdot 20,1 \cdot 98$ & $0.60(0.40$ to 0.91$)$ \\
\hline & Favours treatment & Favo & rs placebo & \\
\hline & 0.6 & & & \\
\hline
\end{tabular}

Rate ratio (treatment/placebo)
TERRANOVA ( $\geq 220$ cells per $\mu \mathrm{L}$ )

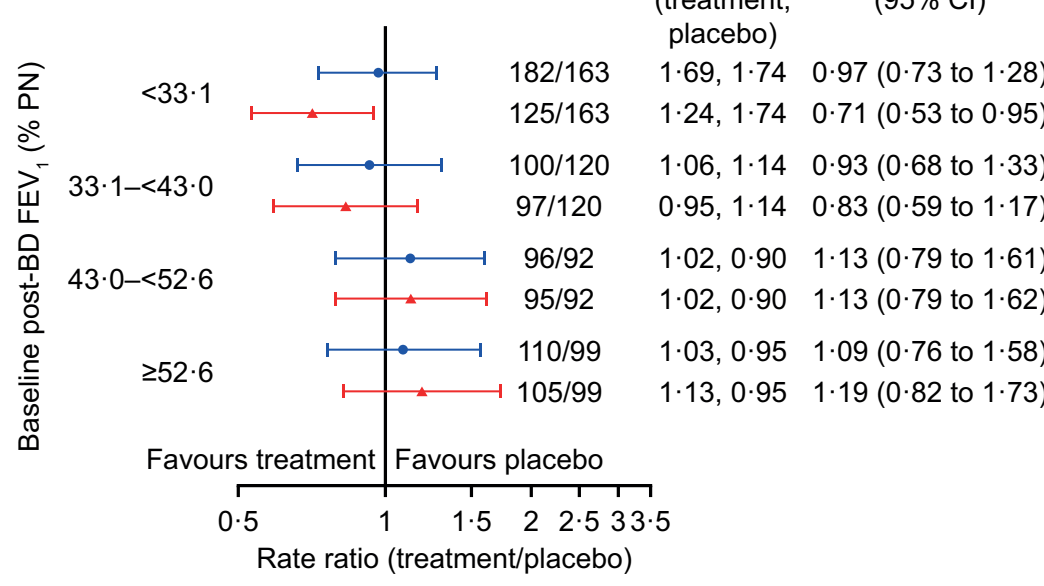

TERRANOVA ( $\geq 220$ cells per $\mu L$ )

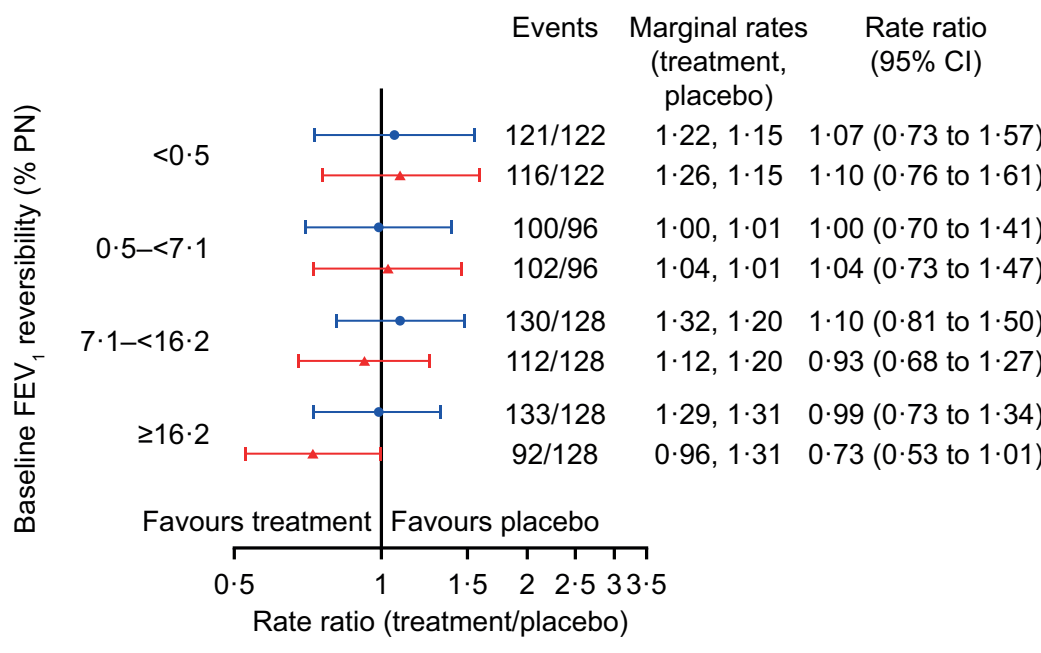

TERRANOVA ( $\geq 220$ cells per $\mu L$ )

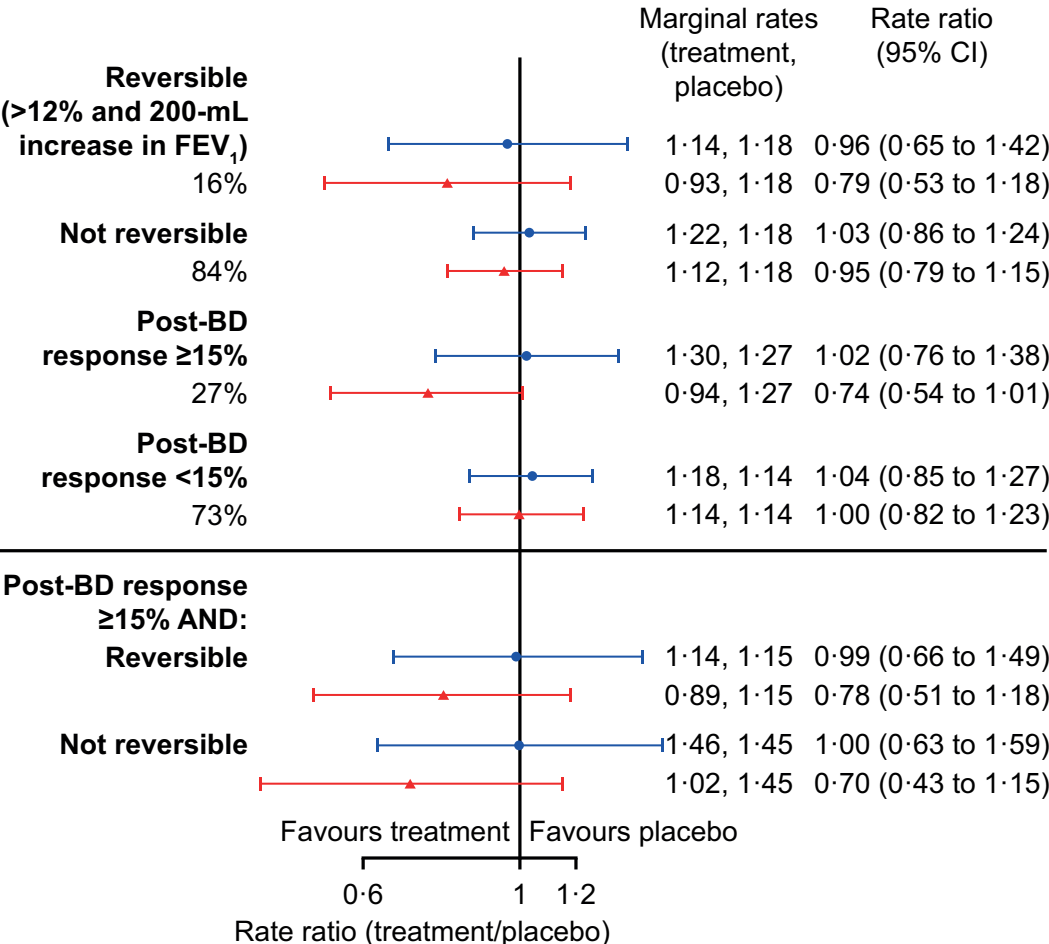

Rate ratio (treatment/placebo) 
Figure 3

Pooled GALATHEA/TERRANOVA data (primary analysis population;

baseline blood eosinophil counts $\geq 220$ cells per $\mu \mathrm{L}$ )

Prior

exacerbations

$\geq 3$

Post
FEV

$\begin{array}{ll} & \geq 40 \% \mathrm{P} \\ & \\ \text { Post-BD } & <15 \% \\ \text { response } & \geq 15 \%\end{array}$

Background medications* $\leq 2$

$<40 \%$ PN

$\geq 40 \% \mathrm{PN}$

$\geq 15 \%$

Dual

Triple

\author{
per $\mu \mathrm{L})$ \\ .
}
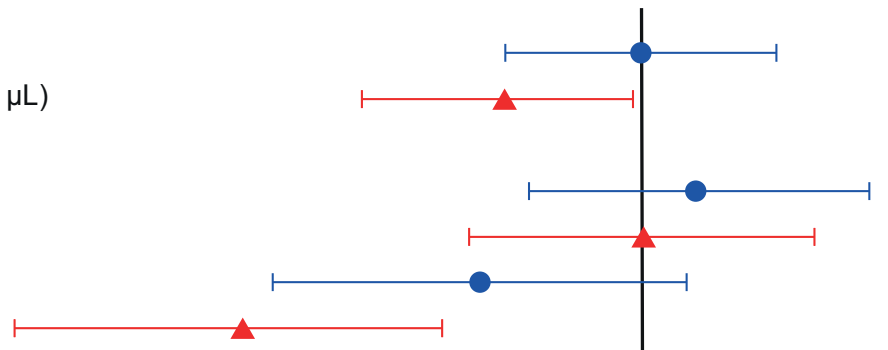

Adjusted rates (treatment, placebo)

$1 \cdot 20,1 \cdot 20$

$1 \cdot 05,1 \cdot 20$

$0.95,0.91$

$0.91,0.91$

$1 \cdot 80,2 \cdot 09$

$1 \cdot 43,2 \cdot 09$

$1 \cdot 43,1 \cdot 60$

$1 \cdot 22,1 \cdot 60$

$1.02,0.94$

$0.93,0.94$

$1 \cdot 17,1 \cdot 11$

$1 \cdot 09,1 \cdot 11$

$1 \cdot 25,1 \cdot 43$

$0.96,1.43$

$0 \cdot 88,0 \cdot 89$

$0.92,0.89$

$1 \cdot 40,1 \cdot 39$

$1 \cdot 13,1 \cdot 39$
Rate ratio

$(95 \% \mathrm{Cl})$

$1.00(0.88$ to 1.13$)$

$0.88(0.77$ to 0.99$)$

$1.05(0.90$ to 1.23$)$

$1.00(0.85$ to $1 \cdot 17)$

$0.86(0.71$ to 1.04$)$

$0.69(0.56$ to 0.83$)$

$0.90(0.76$ to 1.06$)$ $0.76(0.64$ to 0.91$)$ $1.09(0.91$ to 1.30$)$ $0.99(0.83$ to 1.18$)$

$1.06(0.91$ to $1 \cdot 23)$

$0.98(0.84$ to 1.14$)$ $0.87(0.71$ to $1 \cdot 07)$ $0.67(0.54$ to 0.83$)$

$0.98(0.79$ to 1.23$)$ $1.03(0.82$ to 1.28$)$ $1.01(0.87$ to 1.17$)$ $0.81(0.70$ to 0.94$)$

Favours treatment Favours placebo

Rate ratio (treatment/placebo) 
ERR $=41 \%$

(95\% Cl: $16 \%$ to $59 \%)$

$\mathbf{2 . 5 4}(6 \%$ of population)

ERR $=12 \%$

(95\% Cl: $1 \%$ to $23 \%) \quad 1.39$

(100\% of population)

1.39

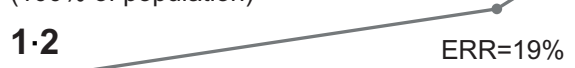

(95\% Cl: $6 \%$ to $30 \%$ )

(63\% of population)

11

$\geq 220$ cells per $\mu \mathrm{L}$ ( $\geq 1$ prior exacerbation)
Add triple

( $\geq 1$ prior exacerbation)
Add $\geq 3$ prior exacerbations
2.38 ERR $=35 \%$

(95\% Cl: $12 \%$ to $52 \%)$ (10\% of population)

$\mathrm{ERR}=26 \%$

(95\% Cl: $-6 \%$ to $48 \%)$

1.89 (9\% of population)

(95\% Cl: $12 \%$ to $44 \%$ )

(19\% of population)

1.86

$E R R=20 \%$

( $95 \% \mathrm{Cl}:-8 \%$ to $41 \%)$

(13\% of population) $\longrightarrow \geq 3$ prior exacerbations post-BD FEV $1<40 \%$ $\geq 3$ prior exacerbations post-BD FEV $_{1} \geq 40 \%$ $\rightarrow \quad \geq 3$ prior exacerbations, post-BD response $<15 \%$ $\rightarrow \geq 3$ prior exacerbations post-BD response $\geq 15 \%$ 

Appendix_TC
Click here to do Appendix_TC
Click here to download Necessary Additional Data: GT Subanalysis appendix rev2_FINAL_tc.docx 
Appendix_CLEAN
Click here to download Necessary Additional Data: Griner et al Supplementary Appendix.pdf 